\section{The N-Acyl Group of Oxonitine}

Oxonitine is an oxidation product of aconitine in which the aconitine $\mathrm{N}$-alkyl has been converted to an $\mathrm{N}$-acyl group. Oxonitine was first formulated by JACOBS $^{1}$ as $\mathrm{C}_{33} \mathrm{H}_{43} \mathrm{O}_{12} \mathrm{~N}$. Since aconitine, which carries a N-ethyl group, and mesaconitine which is the $\mathrm{N}$-methyl analog of aconitine were reported ${ }^{2}$ to yield the same oxonitine, it would seem logical to conclude that oxonitine is an $\mathrm{N}$-formyl derivative. However, JACoBs ${ }^{3}$ later presented evidence which, taken at face value, established rigorously the $\mathrm{N}$-acetyl nature of oxonitine. JACOBS changed the molecular formula of oxonitine to $\mathrm{C}_{34} \mathrm{H}_{45} \mathrm{O}_{12} \mathrm{~N}$ and found that hydrolysis yielded a secondary base. This compound was connected after reacetylation with oxonitine which has never lost the $\mathrm{N}$-acyl group. Just as conclusively as JACoBs has demonstrated the N-acetyl nature of oxonitine, TURNeR ${ }^{4}$ has later proved this compound to be a $\mathrm{N}$-formyl derivative.

Now, if all of the rigorous evidence quoted is indeed correct, the conclusion is inescapable, that oxonitine is a mixture of the $\mathrm{N}$-formyl and $\mathrm{N}$-acetyl derivatives. We have recently described the total synthesis of the racemate $\mathbf{1}^{\mathbf{5}}$. The optically active form of this compound may be obtained not only by a simple degradation of delphinine but also of aconitine ${ }^{6}$. The last step of this degradation consists in the hydrolysis of 2 to 1 in the case of delphinine and 3 or 2 to 1 in the case of aconitine. These steps were originally performed in 1958 (before NMR and TLC) and only the crystalline 1 but not the amorphous 2 and 3 were fully characterized. Since we had to prepare 1 for the purpose of comparison with our synthetic racemate we decided to prepare this compound not only from delphinine but also from aconitine and in this latter case to reinvestigate the precursor 2 and /or 3. This should yield a clean cut decision about the oxonitine $\mathrm{N}$-acyl such as the direct investigation of the highly insoluble nonvolatile and polyfunctional oxonitine cannot provide.

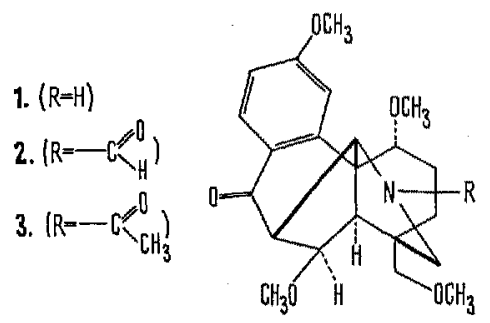

\section{Marmesin or Nodakenetin in Ficus carica $\mathrm{L}$.}

The Moraceae is listed among those plant families rich in coumarin constituents. In particular, psoralen ${ }^{1-3}$, bergapten $2 b, 3$, coumarin itself ${ }^{3}$, and umbelliferone ${ }^{4}$ are recorded in Ficus spp. Recently, DALL'ACQUA et al..$^{5}$ have reported the occurrence of $4^{\prime}, 5^{\prime}$-dihydropsoralen, umbelliferone and an unidentified compound with the characteristic UV-spectrum of an oxigenated coumarin in leaves of Ficus carica. Chromatographic data, the fluorescence under UV-light and the UV-spectrum of their unknown compound matched very well with those given for marmesin in Ruta pinnata (Rutaceae) ${ }^{6}$ and in Lycopersicon esculentum (Solanaceae)" The fact that marmesin has been suggested as a natural intermediate
The $\mathrm{N}$-acyl aromatization product from oxonitine corresponding to 2 or 3 or a mixture of these compounds was prepared as described previously ${ }^{6}$. The material remained amorphous and was homogeneous in TLC. Nevertheless, it showed in the mass-spectrum molecular ions corresponding to both 2 and $3(415,429)$ and in the NMR-spectrum a singlet at $\tau=1.97 \mathrm{ppm}$ corresponding to the formyl hydrogen of pure 2 (obtained either from delphinine or by total synthesis) and a singlet at $\tau=7.9 \mathrm{ppm}$ corresponding to the $\mathrm{N}$-acetyl group of pure 3 (obtained by acetylation of 1 ). The material obviously a mixture of 2 and 3 was refluxed with $10 \%$ conc. hydrochloric acid in methanol. The basic product of this hydrolysis was fully characterized as $\mathbf{1}$ and identified with a sample prepared from delphinine and by total synthesis. The neutral product of the hydrolysis was rigorously identified with the acetylation product of 1. Thus, it has been rigorously proved that the aromatization product of oxonitine is a mixture of 2 and 3 and consequently also 'oxonitine' must be a mixture of the $\mathrm{N}$-acetyl and $\mathrm{N}$-formyl derivatives. Since aconitine is known to contain varying amounts of mesaconitine the explanation of the nature of the oxonitine $\mathrm{N}$-acyl may be at least in part quite trivial and involve the oxidation of the $\mathrm{N}$-methyl and $\mathrm{N}$-ethyl respectively.

Zusammenfassung. Das Oxonitin, welches durch Oxydation von Aconitin mit $\mathrm{KMnO}_{4}$ entsteht, ist ein Gemisch des N-Acetyl- und N-Formyl-Derivats.

K. WIEsner and Lizzie (POON) Jay

Nahural Products Research Center,

The University of New Bunsuick,

Fredericton $(N . B .$, Canada), 8 January 1971.

1 W. A. Jacobs, R. C. Elderfield and L. C. Craig, J. biol. Chem. 128,439 (1936).

2 E. S. Stern, The Alkaloids, Chemistry and Physiology (Ed. R. H. F. Manske, H. C. Holmes; Academic Press, New York 1954 and 1960 ), vol. 6 and 7.

3 W. A. JAcors and S. W. Pelietrer, J. Am. chem. Soc. 76,4048 (1954).

4 R. B. Turner, J. P. Yesceke and M. S. Grbson, J. Am. chem. Soc. $82,5182(1960)$.

5 K. Wiesner, E. W. K. Jay, C. Demerson, T. Kanno, J. KŘePINSKÝ, Lizzie Poon, 'T. Y. R. Tsar, A. Vilím and C. S. Wu, Experientia 26, 1030 (1970).

6 K. Wiesner, M. Götz, D. L. Simmons and L. R. Fowler, Colln Czech, chem. Commun, 28, 2462 (1963).

in the biosynthesis of linear furocoumarins ${ }^{8}$ prompted us to a full characterization of this compound in $F$. carica leaves.

Materials and methods. Fresh leaves (700 g) of F. carica L., collected in September, were homogenized with methanol (3 1) at room temperature. After $3 \mathrm{~h}$ extraction with continuous stirring, the suspension was filtered. The filtrate was concentrated in vacuo to remove the solvent, and the residue was taken up in $60 \%$ methanol. Chlorophylls and other fat-soluble material were removed by extraction into hexane, according to STECK and BAILEY ${ }^{9}$. The residual aqueous methanol solution was concentrated in vacuo, and the aqueous residue was sub- 